\title{
A STATISTICAL STUDY OF ONE THOUSAND PATIENTS.
}

\author{
BY FREDERICK L. HILLS, M. D.,
}

First Assistant Physician, New Hampshire State Hospital, Concord, N. H.

The paper read before the Medico-Psychological Association last year by Dr. Charles W. Pilgrim, Supt. of the Hudson River State Hospital, New York, entitled "The Study of a Year's Statistics" and the discussion following, suggested to me an analysis of the records of the institution with which I am connected. Owing to different local conditions the examination has been made to cover a longer period of time and the lines of inquiry have diverged somewhat from those followed by Dr. Pilgrim; nevertheless there remains sufficient similarity to allow of a comparison as regards certain points presented by the two series of statistics. The records have been very carefully consulted and much time has been given to securing the accuracy of the figures.

During the seven years ending October I, 1900, one thousand different persons were admitted to the New Hampshire State Hospital at Concord. This is the only hospital in the State. The insane are still housed at the county farms in nine counties, where they are under the supervision of the State Board of Commissioners of Lunacy, which transfers all acute and presumably curable cases to the State Hospital. This institution therefore receives practically all the acute and all the disturbed cases.

Of these admissions 533 were men and 467 were women. 37 men and 50 women were admitted two or more times during this period, making the total number of admissions II25. Of the different persons admitted 73.6 per cent of the men and 74.2 per cent of the women were suffering from their first attack. 2I per cent of the men had previously been under treatment, and 24.5 per cent of the women were formerly inmates of this or some other institution. These figures are nearly the same as those reported 
by the State Board of Insanity of Massachusetts for 1900, which gives the number of first admissions to the five public hospitals as 75.16 per cent of the total admissions. Again, it is of interest to note the proportion of the committed insane to the total population of the State. In I895 when the population was approximately 394,009, the total number of insane in the various county farms and in the State Hospital was 712, a ratio of 1 to 553. In 1900 with a total population of 4 I I ,588 the same institutions contained 760 inmates, a ratio of $\mathrm{I}$ to $54 \mathrm{I} \mathrm{I} / 2$. This shows an increase in population at the rate of 4.46 per cent, and of insanity at the rate of 6.74 per cent during the past five years. The total number of insane in the State in 1890 was 982 (including the uncommitted). Since no very small proportion remain outside of the institutions, the actual number of insane individuals at present in the State cannot be determined until the publication of the census of 1900 . Whether the small percentage of increase above noted is due to a real increase in incidence or to a more ready recognition of insanity and a more willing admission of the fact, such as would naturally follow recent public enlightenment upon the subject, is a question still open for discussion. I believe that there is a slight actual increase but a greater apparent increase due to the above causes.

\section{RESIDENCE.}

Returning to the consideration of our 1000 individuals we find that $\mathbf{4 5 7}$ were committed from the incorporated cities. There are but six cities in the State with a population above 9000 , and these sent $385-381 / 2$ per cent of those cummitted. These cities contain 30 per cent of the population of the State. Manchester $(56,987)$ sent 109 and Concord $(19,632)$ I Io, or more than any other city, a much higher percentage in proportion to population than Manchester or Nashua $(23,898)$ which sent but forty-three. This is in part to be explained by the fact that from Concord cases of acute alcoholism are admitted to the Hospital, whereas from the other cities they usually are sent to the county farms. There were in all twenty-nine such cases, twenty of this number coming from Concord. Again, as regards a number of mild senile and chronic cases also committed from Concord the patients would doubtless have been kept at home had the Hospital not been so 
easily accessible. Inquiry into the county residence of these patients shows the largest ratio of admissions to the population to be from Merrimac County where the Hospital is located. Next in order, not of the actual number of commitments but of the ratio of commitments to the population, come Sullivan, Strafford, Rockingham, Cheshire, Hillsboro, Carroll, Grafton, Belknap and Coos. I have looked up the number of committed insane belonging to each county on October I, I900, taking those in the State Hospital and in each county farm on that date and find the following to be the ratio of insane to the population of the county.

TABLE 1.

Counties with Cities of over 9000 Inhabitants.

Merrimac.................... 1 to 382

Cheshire....................... 1 to 407

Rockingham .................... 1 to 429

Hillsboro....................... 1 to 675

Strafford ......................... 1 to 715

A verage for five connties.................. 1 to 521.6

Countifs without Cities of over 9000 inhabitants.

Sullivan ........................ 1 to $\mathbf{3 4 6}$

Grafton ....................... 1 to 530

Carroll .......................... 1 to 603

Belknap...................... 1 to 930

Coos.......................... 1 to 1133

Average for five connties

1 to 708.4

Strafford County has been nearer the head of the list of commitments during the last seven years because, since the destruction of the county asylum by fire in 1893 , all but three of the insane have been sent to the State Hospital. It would appear therefore that the cities send patients in a little higher proportion than the country districts, and that, on the whole, there is a higher percentage of insanity in those counties containing in larger proportion a town-dwelling, rather than a rural, population.

SEASON OF THE YEAR.

29.3 per cent of the patients were admitted in the spring months, 27.8 per cent in the summer, 20.3 per cent in the fall and 22.6 per 
cent in the winter. The months of May, June and September had the largest number of admissions. There was a little difference in this respect on the two sides of the house. May, June and July gave the highest and October, March and April the lowest number of admissions on the male side. On the female side the highest number was in April, August and September and the lowest in October, November and February. The proportion of 57 per cent to 43 per cent between the summer and winter admissions was somewhat greater than that found by Dr. Pilgrim- 54 per cent to 46 per cent. Here it is interesting to recall the observations of Haig-whether or not we accept his conclusions-that the increased occurrence of certain abnormal mental and physical conditions, of mental depression, suicide and murders in the spring and early summer months is coincident with an increase of uric acid in the blood and of uric-acid excretion.

CIVIL CONDITION.

TABLE 2.

Civil Condition of the Insane and General Population ofer 20 YEARS OF AGE.

\begin{tabular}{|c|c|c|c|c|c|c|c|c|}
\hline & \multicolumn{2}{|c|}{ Married. } & \multicolumn{2}{|c|}{ Single. } & \multicolumn{2}{|c|}{ Widowed. } & \multicolumn{2}{|c|}{ Divorced. } \\
\hline & $\begin{array}{l}\text { General } \\
\text { Popu- } \\
\text { lation. }\end{array}$ & $\begin{array}{l}\text { In- } \\
\text { sane. }\end{array}$ & $\begin{array}{c}\text { General } \\
\text { Popu- } \\
\text { lation. }\end{array}$ & $\begin{array}{c}\text { In- } \\
\operatorname{san} \theta\end{array}$ & $\begin{array}{c}\text { General } \\
\text { Popu- } \\
\text { lation. }\end{array}$ & $\begin{array}{c}\text { In- } \\
\operatorname{sane} .\end{array}$ & $\begin{array}{c}\text { General } \\
\text { Popu- } \\
\text { lation. }\end{array}$ & $\begin{array}{c}\text { In- } \\
\operatorname{san} \theta\end{array}$ \\
\hline & Per cent. & $\begin{array}{l}\text { Per } \\
\text { cent. }\end{array}$ & Per cent. & $\begin{array}{c}\text { Per } \\
\text { cent. }\end{array}$ & Per cent. & $\begin{array}{c}\text { Per } \\
\text { cent. }\end{array}$ & Per cent. & $\begin{array}{c}\text { Per } \\
\text { cent. }\end{array}$ \\
\hline $\begin{array}{l}\text { Men ..... } \\
\text { Women .. } \\
\text { Total ... }\end{array}$ & $\begin{array}{l}56 \\
61.4 \\
58.7\end{array}$ & $\begin{array}{l}49 \\
46 \\
47.8\end{array}$ & $\begin{array}{l}24.8 \\
21.8 \\
23\end{array}$ & $\begin{array}{l}35.8 \\
36 \\
36.1\end{array}$ & $\begin{array}{r}5.4 \\
15.1 \\
10.2\end{array}$ & $\begin{array}{l}12.19 \\
15.8 \\
14\end{array}$ & $\begin{array}{l}.67 \\
.86 \\
.7\end{array}$ & $\begin{array}{l}2.4 \\
1.9 \\
2.2\end{array}$ \\
\hline
\end{tabular}

In comparison with the general population of the State above twenty years of age, it is evident that insanity occurs more frequently among the single than among the married. This agrees with the statistics in general upon the subject, but just how far celibacy tends to favor the development of insanity is difficult to determine, for in many cases, as has been pointed out by Tuke, it may be that the mental condition of the individual has prevented marriage and that celibacy has not caused or favored the mental condition. Widowhood is also shown to be conducive to insanity, the proportion in these cases being far higher than among 
the men. The divorced are found also in greater proportion among the insane than among the general population, and here too the men show more frequent incidence. It seems likely that in some instances the insanity is due to moral causes subsequent to the divorce, but in many others it is not improbable that the events leading up to the divorce may have been due to the unrecognized development of the mental alienation.

\section{NATIVITY.}

58.6 per cent of those admitted (6I per cent men and 55.6 per cent women) were natives of New Hampshire; 16.1 per cent were born in other New England States, Maine and Vermont chiefly; 4.6 per cent in other States ; 8.1 per cent were born in Canada, 7.5 per cent in Ireland, and 5.I per cent in other foreign countries. The native population of New Hampshire in I 890 was 80 per cent of the total. It would thus appear that the percentage of native born among the insane is about the same as that among the sane. Of the 20 per cent made up of the foreign-born population 64 per cent were from Canada and 26 per cent from Ireland ; the ratio of Irish born admissions to the Irish born population was I to I99; and of the Canadian born admissions to the Canadian born population $\mathrm{I}$ to $57 \mathrm{I}$.

\section{AGE.}

The average age of the men admitted was 44.01 years; of the women, 44.13 years. 60.8 per cent were admitted during the mcst active period of life, between the ages of 25 and 50 years. Dr. Pilgrim's statistics gave 67 per cent for the same period of life. I 5 per cent of the men and 12 per cent of the women were attacked during the period of adolescence. 21.4 per cent of the men and 19 per cent of the women were over sixty years of age. 40 per cent broke down between the ages of twenty and forty years. These figures conform to the well known facts relative to the more frequent incidence of mental collapse during that period of life when the struggle for existence is beginning to be most wearing, and when a nervous system, predisposed by heredity, improper training or unphysiological early life, succumbs to the increased strain consequent to the cares and anxieties of business and family life. The periods of the normal physiological crises are 
also marked by their damaging effects upon an abnormal nervous system, and so we find the degenerative insanities frequently coming on at the age of adolescence, of the menopause and of senility. The ancient Greek physiologists recognized five climacteric years-the 7 th, the 21 st, the 49 th, the $63 \mathrm{~d}$, and the $8 \mathrm{Ist}$. Substituting the $14^{\text {th }}$ for the 7 th, these years may be fairly taken as approximately marking those climacteric periods whose physiological changes are factors in the development of the psychoses.

OCCUPATION.

All hospital and asylum reports contain long tables showing the occupations of the patients previous to commitment, but such tabulation is of no value unless comparison is made with those persons following similar occupations in the population at large. Below are tables giving the percentage of persons engaged in certain occupations, who were committed together with the percentage of those similarly occupied in New Hampshire according to the census of 1890 .

TABLE 3.

Occopation of Men.

\begin{tabular}{|c|c|c|}
\hline ring and mechanical pursuits.... & $\begin{array}{c}\text { Percentage of } \\
\text { Patients. } \\
\text { 36.5 } \%\end{array}$ & $\begin{array}{c}\text { Percentage of } \\
\text { Population. } \\
36.9 \%\end{array}$ \\
\hline$\ldots \ldots$ & 20.6 & 33 \\
\hline$\ldots \ldots \ldots \ldots \ldots \ldots \ldots \ldots \ldots \ldots \ldots$ & 19 & 18.5 \\
\hline ommercial occupations.................. & $\boldsymbol{9}$ & 14 \\
\hline rofessional occupations ...... & 4.8 & 2.76 \\
\hline To occupation...................... & 7.3 & 17.9 \\
\hline
\end{tabular}

About one-third of the adult male population of the State are farmers, but only one-fifth of the admissions are from this class. It would appear from the figures that the professional men would come first in liability to insanity, the percentage of commitments being almost double that found in the general population. English statistics also give a high ratio for professional men, their number being exceeded only by the soldiers and sailors. The percentage among the laborers and those engaged in manufacturing and mechanical pursuits-mill and factory operatives and the trades-runs about even with the percentage of those employed in like manner in the population at large. 


\section{OCCUPATION IN THE CASE OF WOMEN}

About 53 per cent of the women admitted were housewives and housekeepers. From the census reports it is found that about 49 per cent of the women of the State are thus engaged. 27 per cent of the women of the State have no occupation. The percentage of unemployed among the admissions was I3, a little higher ratio than for the unemployed men. 24 per cent of the female population are engaged in gainful occupations. 32 per cent were thus employed ; 17.5 per cent as domestics, Io per cent as mill operatives and in other manufacturing pursuits; 2.2 per cent as teachers; 2.3 per cent as dressmakers. Marian Harland says in the Independent of May 3, 1900: "In ultra-conscientious New England, the farmers' wives-a large percentage of whom are quondam school mistresses-furnish three-fourths of the population of the State Lunatic Asylums and private retreats, and thrice happy is the farmer who, at forty, has had but one wife and

- kept her. This is statistical, not speculative." This statement is not borne out by the statistics presented in the reports of any.of the New England hospitals. At present in this institution, I5 per cent of the women are the wives of farmers. In the last seven years 23 per cent of the married women admitted were from towns of less than 5000 inhabitants. What proportion of these were farmers' wives I am unable to state with accuracy, but certainly not more than two-thirds. From the report of the Massachusetts State Board of Insanity for 1900 it is found that 976 women were committed to the five State hospitals during the year, of whom 404 were married and 203 were returned as housewives and 25 as farmers' wives. Since the opening of the State Hospital at Middletown, Connecticut, twenty-eight years ago, 40 per cent of the women committed were housewives. As the farming population in Connecticut is only about one-third that of New Hampshire, in proportion to the population, it is probable that not more than 15 per cent or 16 per cent of these were farmers' wives. The reports from the other New England States, although not stating definitely the number of farmers' wives, yet present sufficient evidence to warrant the assertion that not more than 17 per cent of the women admitted from the country districts are farmers' wives and that probably the percentage is even somewhat less. This may be somewhat speculative, but it is no romance. 
ASSIGNED CAUSES.

Among the predisposing causes to insanity, aside from age, occupation, and civil condition which have been already considered, the most prominent are heredity and alcoholism. Heredity includes not only a previous family record of insanity in the direct line or in collateral branches, but also a history of epilepsy, chronic nervous disease, rheumatism, tuberculosis, cancer and, in short, any disease attended by a prolonged lowered bodily vitality. The various drug addictions and excesses of various kinds in the ancestors ought properly to be counted as factors in the heredity of insanity. In this respect, however, our records are defective inasmuch as they show with any approach to accuracy only the past occurrence in the family of insanity, epilepsy and apoplexy. Such an hereditary history was obtained in 29.8 per cent of those admitted. As this figure corresponds closely with that generally obtained in the hospitals throughout the country, and with that found by some English writers, it is evident that upon this point the people of New Hampshire are as sensitive as the rest of mankind. Could all the facts bearing upon heredity be ascertained, it is probable that 40 per cent or 45 per cent of the insanity in New Hampshire would be traceable to hereditary predisposition.

Alcoholism was a predisposing cause in 13 per cent of the men admitted. Only eight women had a history of intemperance, and three of these were cases of acute alcoholism. A syphilitic history was obtained in 3.5 per cent of the patients-2I men and I4 women.

The exciting cause given was; poor health in 17.8 per cent, mental anxiety in 12.9 per cent and overwork in 4.7 per cent.

Of the 467 women, 2.35 per cent had a history of puerperal disturbances and 7.7 per cent of uterine disease to which the mental breakdowns were attributed. The percentage of puerperal insanity is low in New Hampshire. The records of the hospital give an average of 2.18 per cent during the last 30 years. In England the statistics show 6.7 per cent in 68,000 cases during a decade, a percentage almost identical with that given by Kraepelin. Blackford reports 8.2 per cent in the statistics of 1000 patients at the Bristol Lunatic Hospital, and of these 40.4 per 
cent gave an hereditary history. Our records give 34.4 per cent of heredity. The 2nd Annual Report of the Massachusetts State Board of Insanity shows 3.5 per cent of puerperal cases with a history of heredity in 20 per cent. Peterson credits $71 / 2$ per cent of the cases to this cause. For a period of twenty-eight years, in Connecticut, 4.7 per cent are on record ; 3.7 per cent were reported in New York for the year ending Sept. 30, 1898 ; 3.8 per cent at Kalamazoo, Michigan, for the decade ending 1896 . It will thus be seen that the patients admitted from this cause in New Hampshire are much fewer than the statistics in general report. The insanity was due to moral causes (mental anxiety, business and family troubles, death of friends, etc.) in 17.3 per cent-I4 per cent men and 20.3 per cent women. Dr. Pilgrim found 20 per cent of the admissions to the Hudson River Hospital to be due to these factors, and about 33 per cent in which physical causes were responsible for the admission. The latter (diseases of various organs, injuries, the physiological crises, etc.) were exciting causes in 37 per cent of the admissions to our hospital. That these causes were also more active among the women is shown by the ratio of 45 per cent for them as against 30 per cent for the men. Senility was an etiological factor in 6.6 per cent. An hereditary history was obtained in 33 per cent of the senile cases. Probably in 50 per cent of all the patients, these assigned causes were acting on a soil fertilized by heredity, alcoholism and syphilis. In many cases no definite exciting cause could be obtained, particularly in those occurring in early adult life, and the insanity appeared to represent simply the collapse of an organism handicapped at birth, developing precociously with an adolescence marked by the onset of a degenerative insanity.

\section{DURATION OF INSANITY BEFORE ADMISSION.}

40.5 per cent of patients had been insane less than three months. I I. I per cent of patients had been insane 3 to 6 months.

10.5 per cent of patients had been insane 6 months to I year.

37.9 per cent of patients had been insane over I year.

43 per cent of the men and 37 per cent of the women had been insane less than 3 months before admission.

On comparing these figures with those for the seven years 
ending 1880 , it appears that there has been an increase of $71 / 2$ per cent in the admissions of cases of less than three months duration, and that during the last seven years the patients admitted after having been insane for over one year were 8.9 per cent less than twenty years ago. This would seem to demonstrate that the efforts put forth to emphasize the hospital idea and toward improvement in the care and treatment of the insane have in a measure had their effect upon the community and that the Insane Hospital being now looked upon with less dread, its good offices are sought somewhat earlier in the course of the disease.

FORMS OF MENTAL DISEASE.

Acute mania.-The percentage of acute manias among the admissions is the same ( 13 per cent) as was found by Dr. Pilgrim. 59 were men and 73 women. A history of heredity was obtained in 34.8 per cent ; of alcoholism in 8.4 per cent of the men.

The average age of men, with a hereditary history, was 38.3 years ; with no hereditary history, 38.7 years : for women, 32.6 years and 37.2 years respectively.

Recovered, 62-45.7 per cent of men and 48 per cent of women admitted.

Recovered of those with hereditary history, 42 per cent.

Recovered of those without hereditary history, 54 per cent.

Duration of insanity in those who recovered : before admission 2 months ; after admission 6.8 months; total duration 8.8 months.

Improved by treatment 17.4 per cent. Died 9:8 per cent.

Of those discharged recovered 25.9 per cent men and 28.5 per cent women have since relapsed. Berkley says, "All forms of functional mania show a tendency to recur," and while 70 per cent to 80 per cent of the cases recover from the first attack fully 90 per cent relapse after remaining in a normal mental state a few weeks, months or years. Kraepelin states that he has seen but one case of acute mania among a thousand that did not recur and in his classification these cases are divided among a number of clinical groups.

Subacute mania.-1 77 cases, 69 men and 48 women. A history of heredity was obtained in 30 per cent; of alcoholism in 12.8 per cent of men. The average age for men in cases with an 
hereditary history was 45.2 years ; with no hereditary history, 42.9 years : for women, 45.4 years and 37.9 years respectively.

Recovered, 49, or 45 per cent of men and 37.5 per cent of women.

Recovered of those with hereditary history 28.5 per cent.

Recovered of those without hereditary history 47.5 per cent.

Duration of insanity in those who recovered: before admission 4.7 months; after admission 5.4 months; total duration IO.I months.

Improved by treatment 26.4 per cent. Died 4.6 per cent.

Of those discharged recovered 19.3 per cent of the men and 22.2 per cent of the women have since relapsed.

Recurrent mania.-4I cases, 28 men and I 3 women. A history of heredity was obtained in 39 per cent ; of alcoholism in 28 per cent of men. The average age for men, with an hereditary history, was 50.6 years; without an hereditary history, 56.2 years ; for women 40.2 years and 43.3 years respectively.

Recovered, 2 I, or 57 per cent of men and 38.4 per cent of women.

Improved by treatment 14.6 per cent. Died 12 per cent.

Of those discharged recovered, 71.3 per cent of the men and all of the women have since relapsed.

Acute melancholia.-203 cases, 85 men and 118 women. A history of heredity was obtained in 35 per cent ; of alcoholism in 3.9 per cent of men.

Average age for men in cases with an hereditary history, 42.8 years ; with no hereditary history, 45.5 years ; for women, 45.5 years and 42.8 years respectively.

Recovered, 69, or 37.6 per cent of the men and 3 I. 3 per cent of the women.

Recovered of those with hereditary history 35.2 per cent.

Recovered of those without hereditary history 33.3 per cent.

Duration of insanity in those who recovered : before admission 4.6 months; after admission 6 months; total duration 10.6 months.

Improved by treatment 23 per cent. Died 12.3 per cent.

Of those discharged recovered 9.3 per cent of the men and 16.2 per cent of the women have since relapsed. 
Dr. Pilgrim had 33.5 per cent of melancholias among his admissions to 13 per cent of manias, a fact which would point to the admission of many patients in the period of depression preceding a maniacal attack. With us the cases of mania (acute and subacute) were in excess, 25 per cent of mania to 22 per cent of melancholia.

Primary dementia.- Twenty-six patients with this disease were of an average age of 21.6 years. 42.8 per cent of these gave a history of hereditary predisposition. Of the six discharged recovered, two have already relapsed. I have grouped under this heading cases diagnosed as stuporous melancholia, hebephrenia and katatonia-patients that would come within the katatonic and hebephrenic forms of dementia praecox, were Kraepelin's classification adopted.

Cases of the paranoid form of dementia praecox were included under the diagnosis of paranoia, 34 in all, of whom 35 per cent gave a history of heredity. Their average age was 36.7 years. The average age in the 37 cases of chronic delusional insanity was 35.8 years, and in this class 48 per cent of the women and 25 per cent of the men gave a history of heredity.

Paresis. -16 men and 8 women were admitted suffering from paresis. The average age for men was 40.5 years ; for women, 37.3 years.

A history of heredity was obtained in 16.6 per cent ; of syphilis, in 66.6 per cent; of alcoholism, in 68 per cent of the men.

62 per cent of the men were in business or one or other of the professions. Six of the eight women were from the manufacturing towns and all gave a history of an irregular life. In the Journal of Mental Science for January I901, W. W. Ireland reviews an exhaustive paper by Sprengeler, of the Asylum at Wehmen, upon the etiology of paresis. He says : "I must recognize syphilis as by far the most important cause of general paralysis whether it acts directly or indirectly ; but it is not the only cause. I should give the second place to alcoholic intoxication and the third to heredity." Backe states the predisposing cause thus : "A certain general born constitution of the brain, the peculiar nature of which is unknown to us ; further, heredity in the narrow and the wide sense; these prepare the ground which is further 
acted on by syphilis, so that through the influence of several exciting causes, especially emotional disturbance, the disease is brought out." Clevenger says: "Investigation tends to prove that in three-fourths of the cases, syphilis has antedated paretic dementia at some earlier period of life. But it is by no means proved that syphilis is the only predisposing cause. Experience also shows business and professional men more subject to paresis than others." I have no doubt that a still greater percentage than was here ascertained had a syphilitic history. The facts of New Hampshire being largely an agricultural community, of the small proportion of paretics among the admissions and these being almost entirely from the manufacturing towns and cities, tend strongly to support the belief that "civilization and syphilization" are the chief if not the only factors in the etiology of paresis. The majority of the cases of paresis, organic brain disease and paranoia came from the cities. From the country came the larger percentage of acute mania and melancholia, primary dementia and imbecility.

GENERAL RESULTS OF TREATMENT.

Looking now at the general results in these one thousand patients we find that, exclusive of the cases of acute alcoholism, 24.4 per cent were discharged recovered and 17.4 per cent improved, making 41.8 per cent materially benefited by treatment. These figures also are strikingly similar to those of Dr. Pilgrim who obtained 24.21 per cent of recoveries and a total of 42 per cent benefited by treatment.

26.4 per cent of the men and 22 per cent of the women admitted were dischurged recovered. These have subsequently relapsed to the extent of 19.86 per cent for the men and 37.86 per cent for the women. Doubtless more will relapse during the next ten years and it is safe to say that not more than 15 per cent of those discharged recovered will remain well. The average age of the men recovered was 39.7 years and of the women 37.7 years.

Duration of Inganity in those who Recoverid.

$\begin{array}{lccc} & \text { Before Admission. } & \text { After Admission. } & \text { Total. } \\ \text { Men....... } & 6.9 \text { months } & 6.5 \text { months } & 13.4 \text { months } \\ \text { Women.... } & 6.3 \text { months } & 8.1 \text { months } & 14.4 \text { months }\end{array}$


The season of the year appeared to influence the recovery to some extent. More patients recovered in September and in May than in other months. The following table shows more men to have recovered in the summer and spring, more women in the winter and fall. The seasonal difference is much more marked in the men, the rise in the summer months being very great ; but, taking the total recoveries in each season, a steady rise in the recoveries is noted from the fall, through the winter and spring and summer.

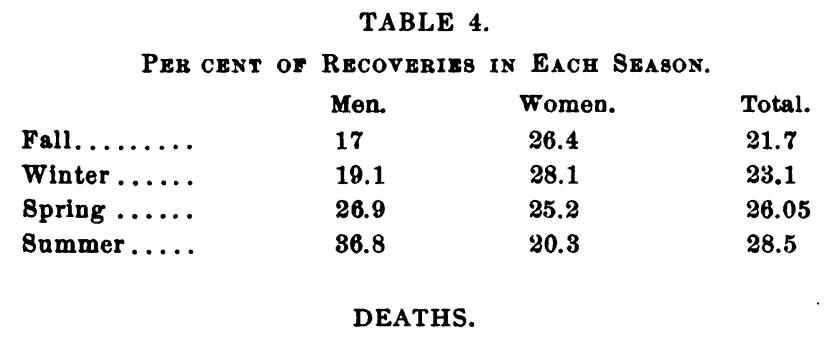

18.I per cent had died under treatment at the end of this period.

The chief causes of death were as follows :

\begin{tabular}{|c|c|c|c|}
\hline Organic brain disease...... & $\begin{array}{l}\text { Per cent of } \\
\text { Men. } \\
45.8\end{array}$ & $\begin{array}{c}\text { Per cent of } \\
\text { Women. } \\
26.3\end{array}$ & $\begin{array}{c}\text { Per cent of } \\
\text { Both. } \\
\mathbf{3 8 . 1}\end{array}$ \\
\hline Senile dementia $\ldots \ldots \ldots \ldots$. & 8.2 & 15.2 & 11.7 \\
\hline Maniacal exhaustion ...... & 6.4 & 6.9 & 6.6 \\
\hline Heart disease. . . . . . . . & 4.5 & 11.1 & 7.8 \\
\hline Phthisis ................ & 4.5 & 5.5 & 5.0 \\
\hline Paresis .... & 9 & 5.5 & 7.25 \\
\hline
\end{tabular}

The duration of hospital residence was for the men 13.3 months and for the women 18.I months. The average age at death 55.4 years for the men and for the women 57.8 years.

More deaths occurred in the winter (32.7 per cent) and spring (24.4 per cent) than in the summer (20.8 per cent) when the mortality was lowest or in the fall (21.8 per cent). I 5.7 per cent of the one thousand patients admitted were discharged not improved, some to be cared for by relatives, but many to go by transfer to the county farm asylums.

Out of a total of 56.4 per cent discharged at the end of this period, 22 per cent have been readmitted. 
On October Ist, 1900, 25.9 per cent of these one thousand patients were remaining. Of these 115 were men and 144 women. 28 men and 30 women were still regarded as curable, leaving 87 men and I14 women or about 75 per cent of the remainder as incurable.

The foregoing figures represent with fair statistical accuracy some facts relative to the insanity occurring in New Hampshire during the last seven years. It has been found difficult and in many cases impossible to make comparisons with the condition in other States-comparisons which would be of interest and often, possibly, of guidance in psychiatric work-on account of the great lack of uniformity in the statistical tables given in American hospital and asylum reports, and in the methods used for the compilation of statistics, a matter in which each institution or State appears to be a law unto itself. 